\title{
Application of Single Wall Carbon Nanotube-wrapped Silica Composite Adsorbents as a Solid Phase Extraction Material to Measure Organophosphorus Pesticides in Water
}

\author{
Hong-Li Lin ${ }^{1}$, Quan-Long $\mathrm{Li}^{2}$, Meng Chen ${ }^{2}$ and Xiong Guan ${ }^{*}, 1$ \\ ${ }^{I}$ Key Laboratory of Biopesticide and Chemical Biology, Ministry of Education, Fujian Agriculture and Forestry \\ University, Fuzhou, 350002, China \\ ${ }^{2}$ College of the Environment and Ecology, Xiamen University, Xiamen, 361005, China
}

\begin{abstract}
In this paper, single wall carbon nanotube (SWCNT) suspensions were added dropwise to silica particles before volatising the solvent to prepare a core-shell composite adsorbent with SWCNTs wrapped around silica particles (SWCNTs@Silica). The composite adsorbent was used as packing for the solid phase extraction (SPE) and the enrichment of organophosphorus pesticides (OPPs) in water. The results indicate the SWCNTs entirely wrap the silica particle surfaces to form SWCNT shells. This preparation method is simpler and more efficient than existing methods. SWCNTs@Silica composite materials can reduce the number of SWCNTs required and improve their utilization. The extraction capacity for OOPs in water was higher than for $\mathrm{C}_{18}$ but below HLB. The developed SPE-GC-FPD method exhibited a limit of detection (LOD) and limit of quantitation (LOQ) of $0.593 \sim 1.759 \mu \mathrm{g} / \mathrm{L}$ and $1.95 \sim 5.80 \mu \mathrm{g} / \mathrm{L}$, respectively and satisfactorily measured Jiulong river and farmland water samples.
\end{abstract}

Keywords: Organophosphorus pesticides, silica gel, single wall carbon nanotubes, solid phase extraction.

\section{INTRODUCTION}

The broad usage of organophosphorus pesticides (OPPs) results in their appearance in environmental waters. Due to potential biosafety risks, many countries, including the US and China, have set clear limits on the environmental residual concentration [1-3]. Currently, the primary pretreatments for OPPs include Soxhlet extraction, ultrasonic extraction and solid phase extraction (SPE) [1-4]. Of these, the China National Standard recommends Soxhlet extraction $[2,3,5]$; however, this method wastes significant amounts of toxic organic solvents; is complicated, time consuming and labour intensive; and cannot extract highly water-soluble polar pesticides. The emergence of new solid phase adsorptive material is expected to allow SPE to replace Soxhlet extraction [6,7]. Numerous reports have used carbon nanotubes (CNTs), which demonstrate excellent adsorption properties [8-11], as SPE packing to extract OPPS in water. However, these studies all use pure CNTs as the packing and consumed a large amount of material (100-200 $\mathrm{mg}$ ) with low utilization, and the minicolumn exhibited significant resistance with a low flow velocity. Composite adsorbents prepared from CNTs and other inorganic or organic carriers via wrapping, embedding and grafting can resolve these issues to some extent. However, these preparation methods are extremely complicated [12-17]. This paper leveraged the self-polymerization of SWCNTs at high

*Address correspondence to this author at the No. 405, Key Laboratory of Biopesticide and Chemical Biology Ministry of Education, Fujian Agriculture and Forestry University, Cangshan District, Fuzhou City, Fujian province, China; Tel: +86 (0)591-83789259; E-mail: guanxfafu@126.com concentrations to prepare a silica composite adsorbent wrapped with SWCNTs (SWCNTs@Silica)via a simple hot air drying method. This composite material inherits both the superior adsorptive properties of SWCNTs and the low column pressure of silica and is expected to lessen the above issues. In this paper, target OPPs with different polarities were used to determine the properties of SWCNTs@Silica, and an analysis method was developed and used to measure environmental water samples.

\section{MATERIALS AND METHODS}

\subsection{Equipment and Reagents}

An Agilent 6890 gas phase chromatograph with a flame photometric detector (FPD), USA with an EQUITY-1701 chromatogram column $(30 \mathrm{~m} \times 0.32 \quad \mathrm{~mm} \times 0.25 \mu \mathrm{m}$, SUPELCO, USA), 12-bit SPE equipment (CNW Co., Germany), electrothermal air blow drying cabinet (Shanghai Yiheng Technical Instrument Co. Ltd., China), stereomicroscope (XTB-1 type, Jiangnan Optical Instrument Factory, China), SWCNTs (Chengdu Organic Chemical Co. Ltd., China, specific surface area $380 \mathrm{~m}^{2} / \mathrm{g}$ ), silica (reagent grade, 100-200 mesh column chromatography silica gel, Qingdao Jiyida Silica Gel Reagent Factory), $\mathrm{C}_{18}$ bonded silica minicolumn (BOND ELUT-C ${ }_{18}, 200 \mathrm{mg}, 3 \mathrm{~mL}$, VARIAN Co., USA), and Oasis HLB SPE minicolumn (200 mg, 6 cc, Waters Co., USA) was used for these experiments.

Mevinphos, dimethoate, malathion, chlorpyrifos and triazophos (analytical grade, Sigma-Aldrich Shanghai Trading Co., Ltd., Shanghai, China); NN-dimethylformamide (DMF, analyticalgrade, Xilong Chemical Co., Ltd., 
Guangdong, China); methanol, acetone, hexane, and ethyl acetate (HPLC grade, Tedia Co., USA); and ultra-pure water (Millipore Simplicity System, Germany) were obtained.

A $10.0 \mathrm{mg}$ sample of each pesticide standard was placed in a $10 \mathrm{~mL}$ brown flask, and dissolved with acetone to obtain $1000 \mathrm{mg} / \mathrm{L}$ single standard stock solutions. A corresponding volume from each stock solution was placed in a single 10 $\mathrm{mL}$ brown flask and diluted with acetone to obtain mixed standard stock solutions of mevinphos, dimethoate, malathion, chlorpyrifos, and triazophos with concentrations of $10,20,30,20$, and $10 \mathrm{mg} / \mathrm{L}$, respectively. Either ultrapure or actual water samples were added during testing according to the requirements to create spiked water samples with different concentrations.

\subsection{Extraction Column Preparation}

The SWCNTs were oxidized and a suspension prepared according to reference [18]. A $5 \mathrm{mg} / \mathrm{mL}$ SWCNT/DMF suspension was obtained. The SWCNT suspension was added dropwise to $200 \mathrm{mg}$ of prepared silica in a beaker until it was barely moistened, and then placed in a $160^{\circ} \mathrm{C}$ hot air drying cabinet for $10 \mathrm{~min}$ to remove the DMF. The beaker was then removed, and a glass rod was used to gently press and separate the clustered particles before again adding the proper suspension dosage. The above process was repeated until all $10 \mathrm{~mL}$ of the suspension was consumed to obtain the SWCNTs@Silica. The SWCNTs@Silica was collected in a beaker and weighed to determine that the SWCNTs@Silica material contained $7.5 \mathrm{mg}$ of SWCNTs, $3.6 \%$ of the total weight. An optical stereomicroscope was used to observe the surface wrapping.

A 200 mg SWCNTs@Silica sample was placed in a 6 $\mathrm{mL}$ empty plastic syringe with sieves at the bottom. Push the sieve from the top to obtain a SWCNTs@Silica SPE minicolumn. Before reusing, the minicolumn was washed with $10 \mathrm{~mL}$ of methanol, acetone, and ethylacetate in sequence and drained for future use.

\subsection{Chromatogram Separation Condition}

The chromatogram column cabinet temperature program: the initial temperature was $80^{\circ} \mathrm{C}$, increased by $20^{\circ} \mathrm{C} / \mathrm{min}$ to $250^{\circ} \mathrm{C}$, held at $300^{\circ} \mathrm{C}$ for $3 \mathrm{~min}$ post run using a $260^{\circ} \mathrm{C}$ sample inlet temperature. The carrier gas (high purity nitrogen) flow rate was $2.0 \mathrm{~mL} / \mathrm{min}$ using a splitless injection and measurement temperature of $230^{\circ} \mathrm{C}$. A phosphorus filter was used with a $60.0 \mathrm{~mL} / \mathrm{min}$ makeup gas (high purity nitrogen) flow rate, $75.0 \mathrm{~mL} / \mathrm{min}$ hydrogen flow rate, and $100 \mathrm{~mL} / \mathrm{min}$ air flow rate. The pre-tests indicate that 5 OPPs can be separated in 8.5 min under such conditions.

\subsection{Column Flow Speed Comparison}

A silica column under a $20 \mathrm{Kpa}$ negative pressure was used as control group to examine the prepared SWCNTs@Silica minicolumn flow speeds. Three minicolumns of each type were used. Every $10 \mathrm{~min}$, a graduated cylinder was used to measure the water volume passing through the extraction minicolumn, and the average flow speed was calculated. This process was repeated thrice for each column.

\subsection{SPE Operation}

In SPE equipment, $3 \mathrm{~mL}$ of methanol and $6 \mathrm{~mL}$ of ultrapure water were used sequentially to activate the minicolumn. The water sample flowed through the minicolumns at the rate of $5 \sim 6 \mathrm{~mL} / \mathrm{min}$, was dried using negative pressure and eluted using a $6 \mathrm{~mL}$ mixed acetone/ethyl acetate solution $(v / v=1: 3)$. The eluent was concentrated to $1 \mathrm{~mL}$ using a nitrogen purge, and a $1 \mu \mathrm{L}$ sample was injected.

\subsection{Measurement the Volume Penetration}

The widely used commercial $\mathrm{C}_{18}$ bonded silica gel and Oasis HLB minicolumns were compared to the SWCNTs@Silica minicolumn. Three penetration volumes for the minicolumns were measured, and it was operated as in section 2.5. All three microcolumns were spiked with 15 $\mu \mathrm{L}$ of the mixed standard stock solution with $1,100,200$, 300,400 and $500 \mathrm{~mL}$ of ultra-pure water. These experiments were repeated 3 times.

\subsection{Effect of $\mathrm{pH}$}

The effect a $\mathrm{pH}$ of $2,4,6$, and 8 for a $100 \mathrm{~mL}$ spiked water sample had on the SWCNTs@Silica minicolumn recoveries was examined for 5 targets.

\subsection{Water Sample Collection and Storage}

Water samples were collected from the north $\left(117.0815^{\circ} \mathrm{E}, 25.1740^{\circ} \mathrm{N}\right)$ and west branches $\left(117.8125^{\circ} \mathrm{E}\right.$, $24.5033^{\circ} \mathrm{N}$ ) of the Jiulong River; farmland water was collected from farms in Shamei Village, Xiang'an, Xiamen $\left(118.3280^{\circ} \mathrm{E}, 24.6178^{\circ} \mathrm{N}\right)$. The water samples were filtered through a $0.45 \mu \mathrm{m}$ glass fiber membrane and stored in a brown bottle at $4^{\circ} \mathrm{C}$ for future use. Measurements were performed with in $12 \mathrm{~h}$.

\section{RESULT AND DISCUSSION}

\subsection{SWCNTs@Silica Characteristics}

A stereomicroscope was used to observe the prepared SWCNTs@Silica. Fig. (1a) shows that a black SWCNT layer wrapped around the SWCNTs@Silica surface, and the particles were uniformly distributed with no hardened block. Fig. (1b) simultaneously shows the colourless transparent silica gel and black SWCNTs@Silica. The SWCNTs@Silica were similarly shaped and sized to the silica particles with coarser and edgy surfaces. This trait may result from the uneven precipitation and polymerization of SWCNTs on the surface. Studies have shown that SWCNTs have small tube diameters, large length-diameter ratios, and strong Van der Waals interactions between tubes with self-polymerization being likely after dispersion [19]. In this paper, an excessive SWCNT concentration in each drop added during the preparation, likely forms a hardened block between particles, while a low-dosages have difficulty wrapping the entire particle, and the SWCNTs layer commonly peels off. The optimal result was obtained when the silica gel is barely moistened. Once hot air removes the solvent, the SWCNTs self-polymerize and deposit on the silica surface due to the 
(a)

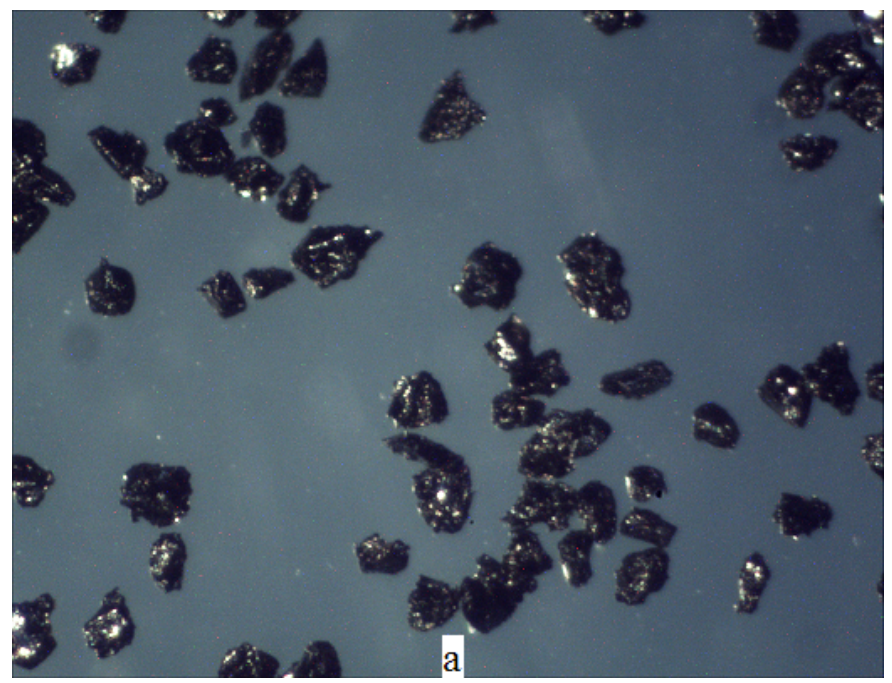

(b)

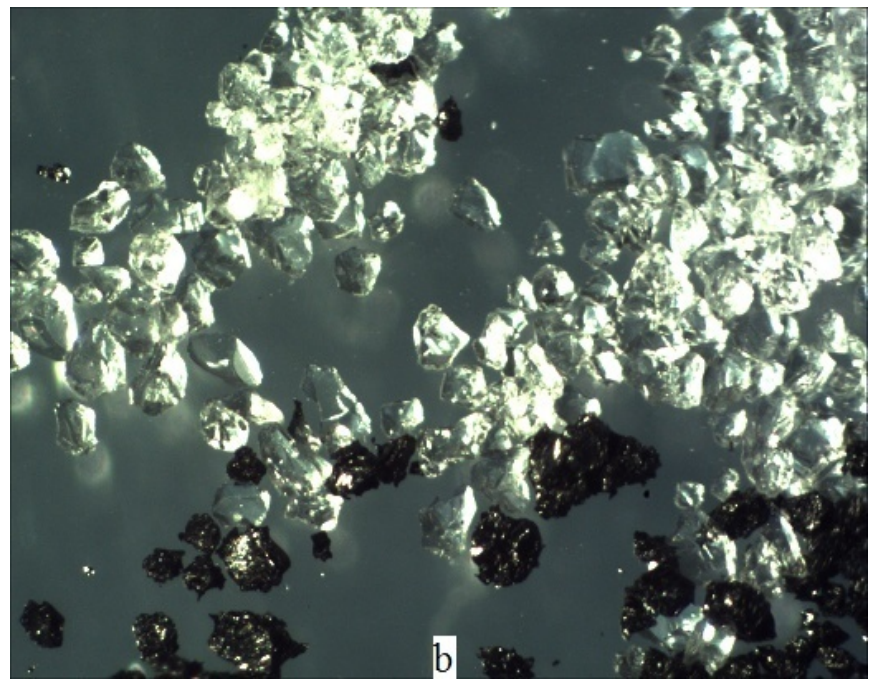

Fig. (1). Images of SWCNTs@Silica and Silica Gel under a Microscope (a) SWCNTs@Silica (×50); (b) Silica gel (colourless) and SWCNTs@Silica (black) (×50).

Van der Waals forces. Multiple precipitations form overlapping SWCNT layers that completely wrap the silica particles without shedding. This method requires few steps and simple operations without requiring adhesives or other additives; the end product has no extra impurities with high SWCNT utilization. This technique is superior to existing preparation methods.

\subsection{Comparison of Column Flow Speed}

Because CNTs are normally powders, packing pure CNTs into a SPE minicolumn yields a large resistance and unstable flow speed that negatively affects the extraction result [20-22]. In this paper, the average measured silica column flow rate was $5.53 \mathrm{~mL} / \mathrm{min}(\mathrm{RSD}=9.0 \%, n=3)$, while the SWCNTs@Silica minicolumn averaged a $7.70 \mathrm{~mL} / \mathrm{min}$ flow rate $(\mathrm{RSD}=10.3 \%, n=3)$. The $\mathrm{T}$ test was under the confidence interval of $95 \%$, which indicates there was no significant difference between two minicolumn flow rates. This result indicates that the SWCNTs@Silica minicolumn inherited the silica minicolumn's low column pressure.

\subsection{Penetration Volume Measurements}

The penetration volume is an important parameter for measuring the SPE minicolumn's adsorption capabilities. Fig. (2) indicates the extraction result for the Oasis HLB packing's that was best followed by SWCNTs@Silica with $\mathrm{C}_{18}$ bonded silica being the worst. For a $300 \mathrm{~mL}$ water sample, the recovery for each target using a HLB minicolumn remained approximately $80 \%-120 \%$. Increasing the water sample volume further reduced the recovery. This result indicated that the minicolumn was penetrated and the targets had begun to leak. Similarly, the SWCNTs@Silica minicolumn's recoveries declined rapidly from $100 \mathrm{~mL}$ to $200 \mathrm{~mL}$ for dimethoate and mevinphos, which are strongly polar; this result indicated that the penetration volume was approximately $100 \mathrm{~mL} . \mathrm{C}_{18}$ bonded silica exhibited the worst

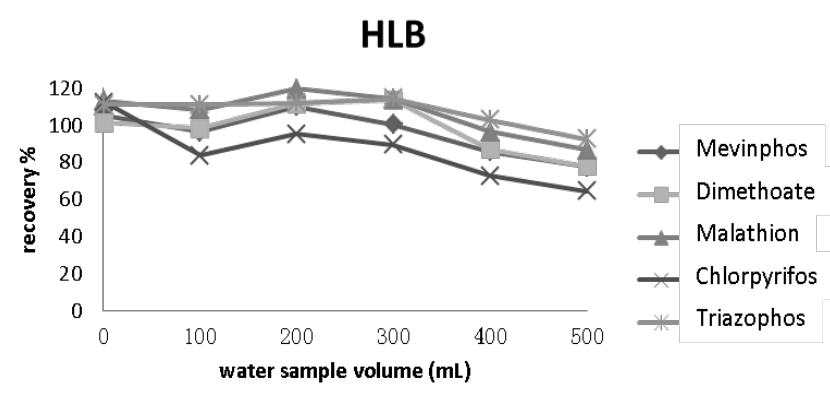

\section{SWCNTs@Silica}

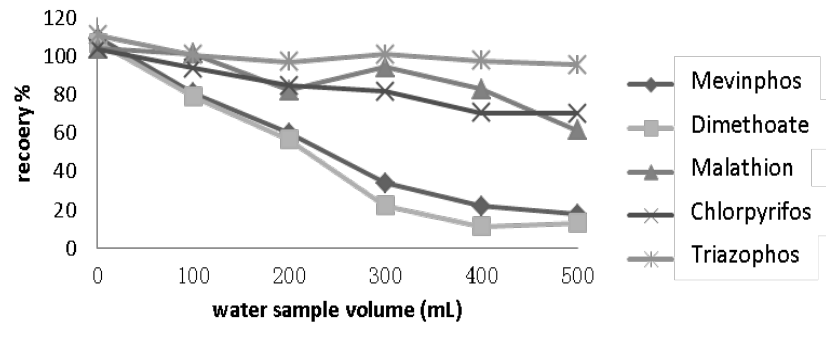

\section{C18 bonded silica}

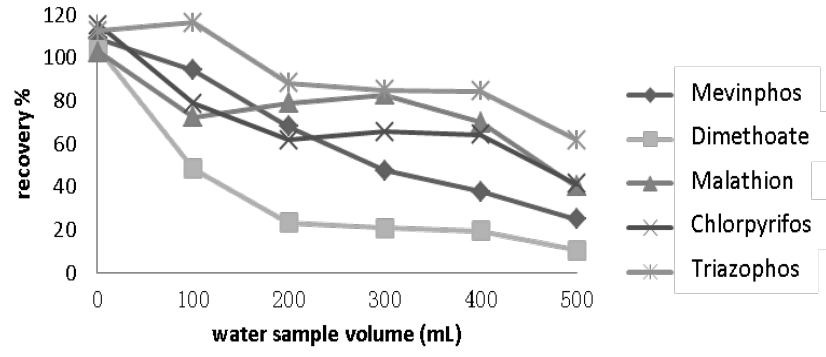

Fig. (2). Relationship between the recovery and water sample volume ( $\operatorname{RSD}<10 \%, n=3$ ). 
extraction result. The recovery of dimethoate rapidly declined from $1 \mathrm{~mL}$ to $100 \mathrm{~mL}$ to below $50 \%$, which indicates the penetration volume was approximately $1 \mathrm{~mL}$.

The 5 selected targets had N-octanol/water partition coefficients ranging from 0.7 4.7. Mevinphos and dimethoate were strongly polar, could mix with water and were difficult to extract. Oasis HLB is a bi-polar packing that can simultaneously extract polar and non-polar compounds. Therefore, it yielded excellent extraction results for all 5 targets. In contrast, $\mathrm{C}_{18}$ bonded silica is a non-polar packing and exhibited the worst extraction results for the two polar compounds, Mevinphos and dimethoate. SWCNTs@Silica contains both oxidized polar groups and its inherent non-polar groups. Therefore, its overall extraction results were better than $\mathrm{C}_{18}$ bonded silica and worse than HLB. However, because SWCNTs@Silica only contain 3.6\% SWCNTs, preparing SWCNTs@Silica with higher concentrations may enhance the extraction capacity.

\subsection{Effect of pH on the Extraction}

SWCNTs@Silica exhibited better extraction result when the $\mathrm{pH}$ value ranged from $2 \sim 6$. Above a $\mathrm{pH}$ of 8 , the chlorpyrifos and malathion recoveries declined significantly.
Therefore, water sample should be processed before measuring to maintain a $\mathrm{pH}$ from $2 \sim 6$.

\subsection{Linear Range, LOD and LOQ}

The SWCNTs@Silica minicolumn was used to extract a $100 \mathrm{~mL}$ water sample with a flow rate of 3-4 $\mathrm{mL} / \mathrm{min}$ using 6 $\mathrm{mL}$ of an acetone/ethyl acetate mixed solution. The eluent was concentrated to $1 \mathrm{~mL}$, a $1 \mu \mathrm{L}$ sample was injected, and a GC-FPD measurement was performed. The analysis for the 5 OPPs in water was developed under these conditions.

A series of $100 \mathrm{~mL}$ ultra-pure spiked water samples with different concentrations were prepared and measured using the developed method. The chromatogram peak area was used to develop a working curve; the linear range and correlation coefficients for the 5 targets were obtained using these working curves. A signal-noise ratio of 3 and 10 times were used to determine the method's LOD and LOQ, respectively; the results are shown in Table 1. All OPPs exhibited excellent linearity in the predefined concentration range with a correlation coefficient $\left(R^{2}\right)$ of $0.9979 \sim 0.9995$ and RSD of $3.2 \% \sim 8.3 \% \quad(n=3)$. The method yielded a LOD of $0.593 \sim 1.759 \mu \mathrm{g} / \mathrm{L}$ and LOQ of $1.95 \sim 5.80 \mu \mathrm{g} / \mathrm{L}$ for the targets.

Table 1. Characteristic data for the developed method.

\begin{tabular}{|c|c|c|c|c|c|}
\hline Targets & Linear Range $(\boldsymbol{\mu g} / \mathbf{L})$ & Correlation Coefficient & LOD $(\boldsymbol{\mu g} / \mathbf{L})$ & LOQ $(\boldsymbol{\mu g} / \mathbf{L})$ & $\mathbf{R S D}(\mathbf{n}=\mathbf{3}, \mathbf{\%})$ \\
\hline \hline Mevinphos & $2 \sim 200$ & 0.9979 & 0.593 & 1.95 & 3.83 \\
\hline Dimethoate & $4 \sim 400$ & 0.9994 & 1.161 & 5.3 & 5.3 \\
\hline Malathion & $6 \sim 600$ & 0.9984 & 1.759 & 2.88 & 6.8 \\
\hline Chlorpyrifos & $4 \sim 400$ & 0.9995 & 0.875 & 0.465 & 3.3 \\
\hline Triazophos & $2 \sim 200$ & 0.9992 & 0.53 & \\
\hline
\end{tabular}

Table 2-1. Recoveries and precision for samples from the north branch of the Jiulong River.

\begin{tabular}{|c|c|c|c|c|}
\hline Targets & Recovery $^{\mathbf{a}}(\mathbf{\%})$ & RSD $^{\mathbf{a}}(\mathbf{\%}, \mathbf{n}=\mathbf{3})$ & Recovery $^{\mathbf{b}}(\mathbf{\%})$ & RSD $^{\mathbf{b}}(\mathbf{\%}, \mathbf{n}=\mathbf{3})$ \\
\hline \hline Mevinphos & 77.3 & 8.2 & 107.5 & 4.9 \\
\hline Dimethoate & 70.4 & 2.0 & 96.4 & 7.3 \\
\hline Malathion & 87.8 & 4.0 & 90.3 & 6.3 \\
\hline Chlorpyrifos & 91.4 & 5.5 & 113.3 & 7.7 \\
\hline Triazophos & 95.2 & 8.7 & 114.7 & 7.6 \\
\hline
\end{tabular}

a. The spiked concentrations were $5,10,15,10$, and $5 \mu \mathrm{g} / \mathrm{L}$ (low concentration), respectively; b. the spiked concentrations were 150, 300, 450, 300, and 150 $\mu \mathrm{g} / \mathrm{L}$ (high concentration), respectively.

Table 2-2. Recoveries and precision for sample from the west branch of the Jiulong river.

\begin{tabular}{|c|c|c|c|c|}
\hline Targets & $\operatorname{Recovery}^{\mathrm{a}}(\%)$ & $\operatorname{RSD}^{\mathrm{a}}(\%, \mathrm{n}=3)$ & $\operatorname{Recovery}^{\mathrm{b}}(\%)$ & $\operatorname{RSD}^{\mathrm{b}}(\%, n=3)$ \\
\hline Mevinphos & 86.0 & 6.4 & 100.7 & 1.4 \\
\hline Malathion & 93.9 & 6.6 & 108.7 & 6.6 \\
\hline Chlorpyrifos & 91.8 & 3.8 & 116.5 & 3.3 \\
\hline
\end{tabular}

a. The spiked concentrations were $5,10,15,10$, and $5 \mu \mathrm{g} / \mathrm{L}$ (low concentration), respectively; b. the spiked concentrations were $150,300,450,300$, and $150 \mu \mathrm{g} / \mathrm{L}$ (high concentration), respectively. 
Table 2-3. Recoveries and precision for farmland water samples.

\begin{tabular}{|c|c|c|c|c|}
\hline Targets & Recovery $^{\mathbf{a}}(\mathbf{\%})$ & RSD $\left.^{\mathbf{a}} \mathbf{( \% ,}, \mathbf{n}=\mathbf{3}\right)$ & Recovery $^{\mathbf{b}}(\mathbf{\%})$ & $\mathbf{R S D}^{\mathbf{b}} \mathbf{( \% , \mathbf { n } = \mathbf { 3 } )}$ \\
\hline \hline Mevinphos & 76.7 & 9.7 & 90.6 & 9.1 \\
\hline Dimethoate & 77.7 & 1.6 & 102.6 & 5.7 \\
\hline Malathion & 81.5 & 4.1 & 119.3 & 5.7 \\
\hline Chlorpyrifos & 102.0 & 1.8 & 112.2 & 3.5 \\
\hline Triazophos & 97.2 & 5.4 & 1.7 \\
\hline
\end{tabular}

a. The spiked concentrations were $5,10,15,10$, and $5 \mu \mathrm{g} / \mathrm{L}$ (low concentration), respectively; b. the spiked concentrations were $150,300,450,300$, and $150 \mu \mathrm{g} / \mathrm{L}$ (high concentration), respectively.

\subsection{Actual Water Sample Measurements}

No target was detected when the developed method was used to measure water from the west and the north branches of the Jiulong river and farmlands. Recoveries from 3 water samples were measured after adding a standard, and the results are shown in Tables 2-1, 2-2 and 2-3. These tables indicate that the targets all had spiked recoveries between $70 \%-110 \%$ with a $10 \%$ precision $(\mathrm{RSD} \%, \mathrm{n}=3)$. Samples with higher spiked concentrations had slightly higher recoveries than those with lower spiked concentrations. This method can be applied to actual water sample measurements with satisfactory result.

\section{CONFLICT OF INTEREST}

The authors confirm that this article content has no conflict of interest.

\section{ACKNOWLEDGEMENTS}

This work is supported by the National 863 project of China (2011AA10A203).

\section{REFERENCES}

[1] EPA Method 8141B, Organophosphorus compounds by gas chromatography, 2007.

[2] GB 5749-2006, Standards for drinking water quality, 2006

[3] GB 3838-2002, Environmental quality standards for surface water, 2002.

[4] Nomen R, Sempere J, Chavez F, de Lopez NA, Rovira MD. Measurement of pollution levels of organochlorine and organophosphorus pesticides in water, soil, sediment, and shrimp to identify possible impacts on shrimp production at Jiquilisco Bay. Environ Sci Pollut R 2012; 19: 3547-55.

[5] GB 13192-1991, Water quality-Determination of organic phosphorous pesticide in water-Gas chromatography.

[6] Ravelo-Perez LM, Herrera-Herrera AV, Hernandez-Borges J, Rodriguez-Delgado MA. Carbon nanotubes: Solid-phase extraction. J Chromatogr A 2010; 1217: 2618-41.

[7] Pyrzynska K. Carbon nanotubes as sorbents in the analysis of pesticides. Chemosphere 2011; 83: 1407-13.

[8] Li Q, Wang X, Yuan D. Solid-phase extraction of polar organophosphorous pesticides from aqueous samples with oxidized carbon nanotubes. J Environ Monitor 2009; 11: 439-44.
[9] Hadjmohammadi MR, Peyrovi M, Biparva P. Comparison of C18 silica and multi-walled carbon nanotubes as the adsorbents for the solid-phase extraction of Chlorpyrifos and Phosalone in water samples using HPLC. J Sep Sci 2010; 33: 1044-51.

[10] Asensio-Ramos M, Hernandez-Borges J, Borges-Miquel TM, Rodriguez-Delgado MA. Evaluation of multi-walled carbon nanotubes as solid-phase extraction adsorbents of pesticides from agricultural, ornamental and forestal soils. Anal Chim Acta 2009; 647: 167-76.

[11] Lopez-Feria S, Cardenas S, Valcarcel M. One step carbon nanotubesbased solid-phase extraction for the gas chromatographic-mass spectrometric multiclass pesticide control in virgin olive oils. J Chromatogr A 2009; 1216: 7346-50.

[12] Surez B, Simonet B, Rdenas SC, Valarcel M. Determination of nonsteroidal anti-inflammatory drugs in urine by combining an immobilized carboxylated carbon nanotubes minicolumn for solidphase extraction with capillary electrophoresis-mass spectrometry. J Chromatogr A 2007; 1159: 203-07.

[13] Du Z, Yu Y, Yan X, Wang J. Isolation and pre-concentration of basic proteins in aqueous mixture via solid-phase extraction with multiwalled carbon nanotubes assembled on a silica surface. Analyst 2008; 133: 1373-79.

[14] Menna E, Negra FD, Prato M, Tagmatarchis N, Ciogli A, Gasparrini F, Misiti D, Villani C. Carbon nanotubes on HPLC silica microspheres. Carbon 2006; 44: 1609-13.

[15] Andre C, Gharbi T, Guillaume YC. A novel stationary phase based on amino derivatized nanotubes for HPLC separations: theoretical and practical aspects. J Sep Sci 2009; 32: 1757-64.

[16] Liang X, Liu S, Liu H, Liu X, Jiang S. Layer-by-layer self-assembled multi-walled carbon nanotubes/silica microsphere composites as stationary phase for high-performance liquid chromatography. J Sep Sci 2010; 33: 3304-12.

[17] Zhong Y, Zhou W, Zhang P, Zhu Y. Preparation, characterization, and analytical applications of a novel polymer stationary phase with embedded or grafted carbon fibers. Talanta 2010; 82: 1439-47.

[18] Li Q, Wang X, Yuan D. Preparation of solid-phase microextraction fiber coated with single-walled carbon nanotubes by electrophoretic deposition and its application in extracting phenols from aqueous samples. J Chromatogr A 2009; 1216: 1305-11.

[19] Girifalco LA, Hodak M, Lee RS. Carbon nanotubes, buckyballs, ropes, and a universal graphitic potential. Phys Rev B 2000; 62: 13104-10.

[20] Suarez B, Santos B, Simonet B, Cardenas S, Valcarcel M. Solid-phase extraction-capillary electrophoresis-mass spectrometry for the determination of tetracyclines residues in surface water by using carbon nanotubes as sorbent material. J Chromatogr A 2007; 1175: 127-32.

[21] Valcarcel M, Rdenas SC, Simonet B, Moliner-Martinez Y, Lucena R. Carbon nanostructures as sorbent materials in analytical processes. Trac-Trend Anal Chem 2008; 27: 34-43.

[22] Boonjob W, Mir M, Segundo MA, Cerda V. Flow-through dispersed carbon nanofiber-based microsolid-phase extraction coupled to liquid chromatography for automatic determination of trace levels of priority environmental pollutants. Anal Chem 2011; 83: 5237-44.

This is an open access article licensed under the terms of the Creative Commons Attribution Non-Commercial License (http://creativecommons.org/licenses/ by-nc/4.0/) which permits unrestricted, non-commercial use, distribution and reproduction in any medium, provided the work is properly cited. 